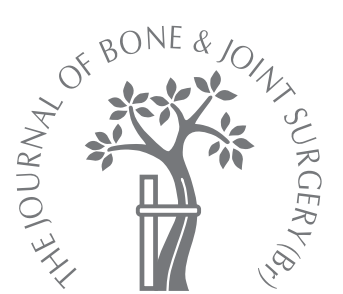
A. J. Laing,
J. P. Dillon, E. T. Condon, J. C. Coffey, J. T. Street, J. H. Wang, A. J. McGuinness, H. P. Redmond

From Cork University Hospital, Cork, Republic of Ireland

\title{
A systemic provascular response in bone marrow to musculoskeletal trauma in mice
}

Post-natal vasculogenesis, the process by which vascular committed bone marrow stem cells or endothelial precursor cells migrate, differentiate and incorporate into the nacent endothelium and thereby contribute to physiological and pathological neurovascularisation, has stimulated much interest. Its contribution to neovascularisation of tumours, wound healing and revascularisation associated with ischaemia of skeletal and cardiac muscles is well established. We evaluated the responses of endothelial precursor cells in bone marrow to musculoskeletal trauma in mice.

Bone marrow from six C57 Black 6 mice subjected to a standardised, closed fracture of the femur, was analysed for the combined expression of cell-surface markers stem cell antigen $1\left(\mathrm{sca}^{-1^{+}}\right)$and stem cell factor receptor, CD117 (c-kit $\left.{ }^{+}\right)$in order to identify the endothelial precursor cell population. Immunomagnetically-enriched sca-1+ mononuclear cell $\left(\mathrm{MNC}^{\text {sca-1+}}\right.$ ) populations were then cultured and examined for functional vascular

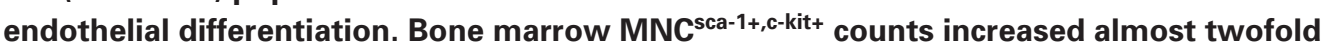
within 48 hours of the event, compared with baseline levels, before decreasing by 72 hours.

Sca- $1^{+}$mononuclear cell populations in culture from samples of bone marrow at 48 hours bound together Ulex Europus-1, and incorporated fluorescent 1,1'-dioctadecyl- 3,3,3,'3' tetramethylindocarbocyanine perchlorate-labelled acetylated low-density lipoprotein intracellularily, both characteristics of mature endothelium.

Our findings suggest that a systemic provascular response of bone marrow is initiated by musculoskeletal trauma. Its therapeutic manipulation may have implications for the potential enhancement of neovascularisation and the healing of fractures.

Healing of fractures is a complex phenomenon of repair which recapitulates many aspects of skeletal development in the embryo. Endochondral and intramembranous ossification, two distinct interactive responses, which are ultimately responsible for bone healing, require an adequate blood supply. Neovascularisation of the fracture is therefore a prerequisite for normal healing. The formation of new blood vessels in adults has traditionally been understood to result exclusively from angiogenesis, the process of local proliferation, migration, and remodelling of endothelial cells (ECs) from a mature pre-existing endothelium. ${ }^{1,2}$ Efforts to enhance neovascularisation by supplementation with recognised pro-angiogenic cytokines have yielded promising results. ${ }^{3-6}$ However, the resident population of ECs which is responsive to available levels of angiogenic growth factors may potentially limit the extent to which supplementation enhances tissue neovascularisation. Situations which compromise endothelial function and angiogenesis are well recognised as contributing to delayed healing of the fracture and atrophic nonunion. These include diabetes mellitus, ${ }^{7-10}$ hypercholesterolaemia, ${ }^{11}$ smoking $^{12,13}$ and advancing age. ${ }^{14,15}$

The recent recognition that vasculogenesis, a process by which stem cells in bone marrow which are committed to the vascular endothelial lineage, termed endothelial precursor cells (EPCs), can migrate from the marrow to a site of developing neovasculature in adults, has stimulated much interest. ${ }^{16-18}$ This was previously believed to be an exclusively embryonic process. However, EPCs have now been shown to differentiate and incorporate into the nascent endothelium at sites of post-natal physiological and pathological formation of new vessels. ${ }^{18}$

Dual cell-surface antigen expression (stem cell antigen $1\left(\mathrm{sca}-1^{+}\right)$and CD117, stem cell factor receptor $\left.\left(\mathrm{c}-\mathrm{kit}^{+}\right)\right)$identifies a population of murine EPCs which participate in neovascularisation and give rise to functional endothelial cells in models of ischaemia. ${ }^{19-22}$ Our aims 


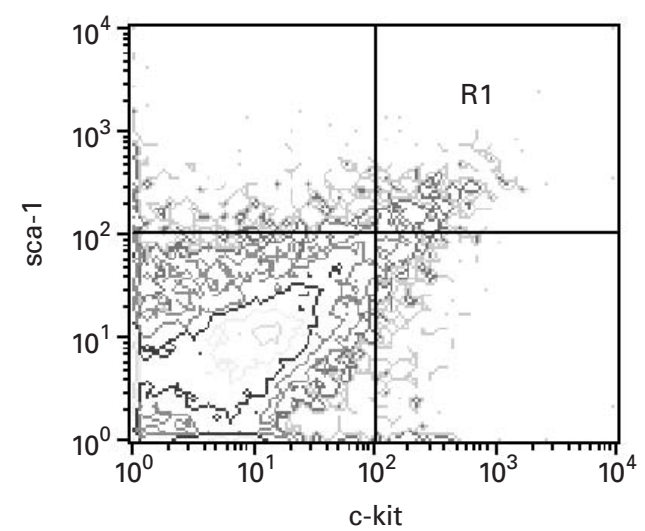

Fig. 1

Diagram of stem cell antigen 1 (sca-1)(ly6A/E)+ CD117 stem cell factor receptor (c-kit) + dual-positive quadrants. Samples were subjected to a two-dimensional side-scatter fluorescence dot-plot analysis.

were to demonstrate a systemic vascular cellular response in bone marrow to the fracture of long bones by the mobilisation of sca- $1^{+} / \mathrm{c}-\mathrm{kit}^{+}$mononuclear cells $\left(\mathrm{MNCs}^{\mathrm{sca}-1+, \mathrm{c}-\mathrm{kit}+}\right)$ and to demonstrate their differentiation into phenotypic and functional endothelial cells.

\section{Materials and Methods}

Murine fracture model. A murine fracture model was used to examine systemic changes in bone marrow in response to musculoskeletal trauma. Six C57 Black 6 female mice (Jackson Laboratories, Bar Harbour, Maine) were randomised to an unfractured control group, while six mice per time point were randomised to a group with an isolated closed fracture of the shaft of the right femur produced by using a standardised three-point loading technique. ${ }^{23}$ The recognised model for this involved intramedullary fixation of the femur before fracture. ${ }^{23}$ However, in view of the surgical trauma involved in inserting this device, a confounding traumatic stimulus in itself, the fracture group had external splinting of the extended injured hind limb provided by the application of bulky circumferential tape (3M micropore, 3M, Aycliffe, Co. Durham). All the procedures were performed under licence from the Department of Health of Ireland and with the approval of the Ethics Committee of Cork University Hospital.

The mice were anaesthetised with intraperitoneal xylazine $(10 \mathrm{mg} / \mathrm{kg})$. Their right hip, thigh and knee were shaved. A three-point loading technique was used to create a consistent, closed, comminuted fracture of the midshaft of the femur. ${ }^{23}$ Post-operatively, all the animals received oral ketoprofen $(2.5 \mathrm{mg} / \mathrm{kg}$ to $5.0 \mathrm{mg} / \mathrm{kg} 12$ hourly) for relief from pain and all were housed individually. After 24, 48 and 72 hours, all animals were killed by cervical dislocation. An identical protocol, excluding the fracture was followed for the control group.
Bone marrow harvest and precursor quantification by flow cytometric analysis. The right femur was dissected to confirm the presence of a fracture and the intact left femur and both tibiae were harvested. In order to exclude any local response of the bone marrow to the injury, the marrow was not retrieved from the fractured limb. A $18 \mathrm{G}$ cannula was introduced into the marrow cavity of each of the other bones distally, and the marrow was flushed of its contents with $5 \mathrm{ml}$ of phosphate-buffered saline (PBS) and 2\% fetal bovine serum (FBS). ${ }^{21}$ The suspension comprising the combined marrow contents for each individual was then filtered to remove any bony debris, centrifuged at $400 \mathrm{~g}$ for ten minutes and resuspended in $3 \mathrm{ml}$ of medium. ${ }^{21}$ The mononuclear cell layer was then isolated by density-gradient centrifugation, washed twice in PBS and resuspended in PBS to a concentration of $10^{7}$ cells $/ \mathrm{ml}$.

Two cell markers were used for the identification of the EPCs. These were chosen based upon their documented roles in vasculogenesis. ${ }^{19,22}$ The sca-1 protein (or lymphocyte activation protein-6A (ly-6A)) was originally identified as an antigen with increased expression on the surface of activated lymphocytes which facilitates cell signalling. ${ }^{24-26}$ The C-kit receptor tyrosine kinase plays an essential role in regulating proliferation, survival and migration of haematopoietic stem and progenitor cells. ${ }^{20,27,28}$

A viable cell count was performed using Trypan Blue (Stemcell Technologies Inc., Vancouver, Canada) and the cells were resuspended in the medium to $10^{5}$ cells $/ \mathrm{ml}$. The sca-1(lymphocyte antigen complex locus A/EE ly6A/E)+ckit(cluster degeneration (CD) antigen 117 (CD117)) ${ }^{+}$population was quantified at all time points. Mononuclear cells were stained with a phycoerythrin (PE)-conjugated anti-sca and fluorescein-isothiocyanate (FITC)-conjugated anti-ckit antibodies. To avoid non-specific staining, cells were stained with PE- and FITC-conjugated mouse immunoglobulin $\mathrm{G} 1\left(\mathrm{I}_{\mathrm{g}} \mathrm{G}_{1}\right)$. The samples were subjected to a twodimensional side scatter-fluorescence dot-plot analysis (FACScan; Becton-Dickinson, Oxford, United Kingdom). After appropriate gating, the sca-1(ly6A/E)+c-kit(CD117)+cell population was quantified and expressed as the number of cells per $10^{6}$ white blood cells (Fig. 1).

Immunomagnetic-negative selection for murine MNC $^{\text {sca-1+ }}$ and culture. Bone marrow was harvested after 48 hours as described. The cells were resuspended to $5 \times 10^{7}$ nucleated cells/ml in PBS. A centrifugation-separation technique (Stemcell Technologies) was used for murine haematopoietic progenitor cell enrichment. An antibody cocktail bound the unwanted cell populations which were pelletted on centrifugation. ${ }^{21}$ The enriched cells formed a band at the centrifuge density medium-PBS interface and were removed into a separate tube in which they were washed with PBS and centrifuged at $200 \mathrm{~g}$. The pellet was resuspended in PBS and $2 \%$ FBS. The enriched MNCs $\left(5 \times 10^{3}\right.$ cells $\left./ \mathrm{ml}\right)$ were cultured on fibronectin $(2.5 \mu \mathrm{g} / \mathrm{ml})$-coated chambers (Biocoat; Becton-Dickinson) in an endothelial basal cell medium (Clonetics, Cambrex Bioscience, Baltimore Inc., 


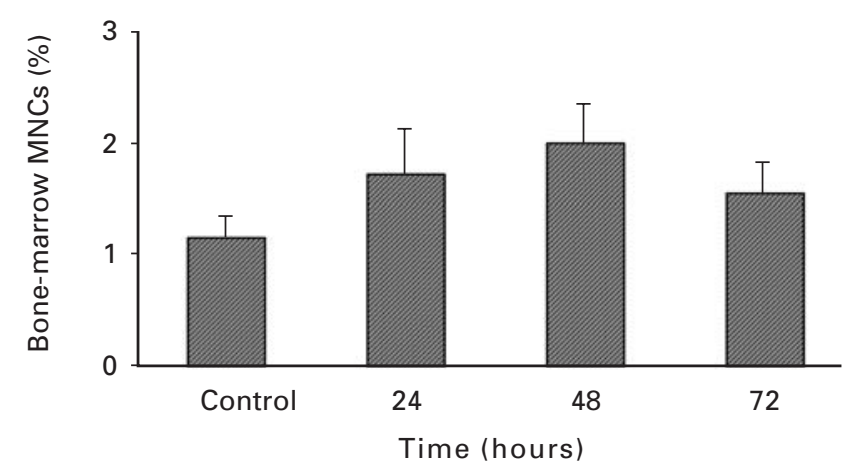

Fig. 2

Graph showing the time course of dual-positive bone marrow, mononuclear cell (MNC) counts expressing stem cell antigen 1 and c-kit antigen ( $n=6$ per group).

Baltimore, Maryland) containing 2\% FBS and antibiotics (streptomycin and penicillin) in $5 \% \mathrm{CO}_{2}$ at $37^{\circ} \mathrm{C} .{ }^{29}$ The culture medium was changed every 48 hours. After seven days, cultures were assessed for the functional properties of mature ECs by incubation in $10 \mu \mathrm{g} / \mathrm{ml}$ of 1,1 '-dioctadecyl3,3,3',3'-tetramethylindocarbocyanineperchlorate-labelled low-density lipoprotein (DiI- Ac-LDL; Molecular Probes, Eugene, Oregon) for four hours at $37^{\circ} \mathrm{C}$. Endothelial cells incorporating DiI-Ac-LDL degrade the lipoprotein and the DiI (fluorescent probe) accumulates in the intracellular membranes. Similarly, cells were also incubated with FITCconjugated Ulex Europeus-1 (UEA-1; Santa Cruz Biotechnology, Santa Cruz, California) at $50 \mu \mathrm{g} / \mathrm{ml}$ for one hour at $37^{\circ} \mathrm{C}$ to determine membrane binding, a functional property of the vascular endothelium. ${ }^{19,21,30}$

Statistical analysis. Data were subjected to one-way analysis of variance and pairwise multiple comparison procedures (Holm-Sidak method (Systat Software Inc., San Jose, California)) to determine statistical significance. Values were expressed as the mean and standard deviation, and a p-value $<0.05$ was considered to be significant.

\section{Results}

Figure 2 gives the time course of dual-positive bone-marrow $\mathrm{MNC}^{\text {sca- }-1 / \mathrm{c}-\mathrm{kit}+}$ expression in the study group. $\mathrm{MNC}^{\text {sca- }}$ $1 / \mathrm{c}$-kit+ levels in the bone marrow increased from $1.16 \%$ (SD 0.19 ) at the baseline control level to $1.72 \%$ (SD 0.41) at 24 hours $(\mathrm{p}=0.007)$, peaking at 48 hours after fracture $(1.99 \%($ SD $0.36, p=0.0002)$ and decreasing at 72 hours (1.54 SD $0.29 \mathrm{p}=0.06)$.

Immunomagnetic negative selection yielded $\mathrm{MNC}^{\text {sca-1+ }}$ cell-enriched populations in excess of five times that of the baseline levels (less than 2.0\%).

From cultured bone-marrow MNCs ${ }^{\text {sca- }-1 / c-k i t+}$ numerous cells were found to incorporate fluorescent DiI-Ac-LDL and to bind UEA-1, functional properties specific to mature endothelial cells (Fig. 3). ${ }^{3}$

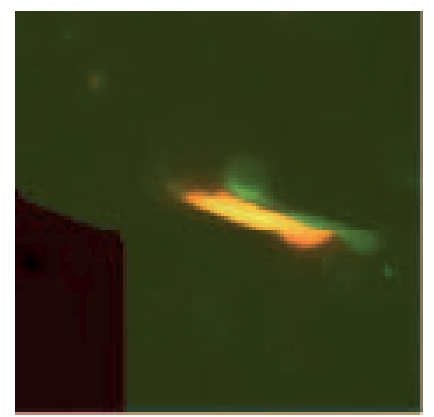

Fig. 3a

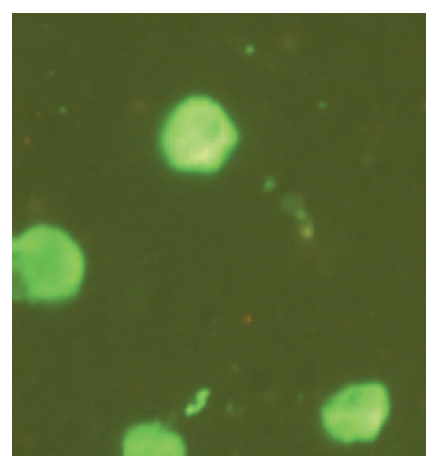

Fig. 3b

Photomicrographs showing a) spindle cells incorporating fluorescent 1, $1^{\prime}$-dioctadecyl-3,3,3', $3^{\prime}$-tetramethylindocarbo-cyanineperchloratelabelled low density lipoprotein, and b) binding fluorescent Ulex Europeus 1.

\section{Discussion}

While angiogenesis has traditionally been accepted as the only process of adult vascular endothelial turnover, the description of the isolation of progenitor ECs by Asahara et $\mathrm{al}^{16}$ has provoked much interest in the concept of post-natal vasculogenesis and the ability of cells derived from adult bone marrow to contribute to the formation of new blood vessels. Experiments with murine bone marrow transplants have demonstrated the incorporation of bone-marrowderived EPCs into foci of physiological and pathological neovascularisation in growing tumours, healing wounds and ischaemic skeletal and cardiac muscles. ${ }^{18}$ Matrigel wound models have demonstrated that up to $22 \%$ of new vessel endothelium is derived from bone marrow. ${ }^{31}$

The vasculogenic responses of bone marrow to musculoskeletal trauma have not been previously evaluated. We hypothesised that musculoskeletal trauma acts as a stimulus for the production of cells in the bone marrow capable of differentiating into phenotypic and functionally mature ECs. Using a standardised murine closed-fracture model, we sought to quantify this response and to determine the differentiation of the ECs. 
Jackson et $\mathrm{al}^{22}$ found by transplantation of bone marrow the lacZ gene-positive sca- $1^{+} / \mathrm{c}-\mathrm{kit}{ }^{+}$cells could participate in myocardial revascularisation after the induction of ischaemia by occlusion and reperfusion of coronary arteries. Bailey et $\mathrm{al}^{19}$ demonstrated that adult bone-marrowderived stem cells $\left(\mathrm{c}-\mathrm{kit}^{+}, \mathrm{sca}-1+\right)$ gave rise to functional ECs.

We quantified dual-positive MNC expression at 72 hours after the inciting event. Bone-marrow $\mathrm{MNC}^{\mathrm{sca}-1+, \mathrm{c}-\mathrm{kit}+}$ counts increased significantly at 24 hours compared with control baseline levels, peaking at 48 hours. This elevation persisted at 72 hours, but not to a significant level ( $\mathrm{p}=$ $0.06)$.

Because $\mathrm{MNC}^{\text {sca-1+,c-kit+ }}$ gave rise to EPCs, we attempted to demonstrate differentiation of ECs on cell culture. In our study, bone-marrow MNCs enriched by immunomagnetic selection for sca-1 in culture expressed EC lineage functional activity (UEA-1 binding and DiI-Ac-LDL uptake) consistent with that of mature ECs.

The molecular mechanisms responsible for vasculogenesis are not completely understood. Gene-targeting studies have shown vascular endothelial growth factor (VEGF) to be essential for embryonic vasculogenesis. ${ }^{32-34}$ Evidence supporting a role in modulating adult EPC kinetics has also been established. Intraperitoneal administration of recombinant VEGF gives a marked increase in MNCs in peripheral blood, both positive for EC-specific antigens and AcLDL intracellular incorporation. Neutralising antibody against recombinant human (rh)VEGF protein completely attenuates these effects. ${ }^{17}$ VEGF has also been demonstrated to enhance in a dose-dependent manner the proliferation and migration of EPCs in culture as well as to exert chemotactic activity on mononuclear cells in bone marrow. ${ }^{17,35}$

Our study has a number of limitations. First, despite demonstrating their mobilisation within the bone marrow, we do not know whether EPCs participate in neovascularisation at the site of musculoskeletal trauma. We have previously demonstrated an increase in circulating peripheral blood EPCs after closed tibial fracture in humans, ${ }^{36}$ but because of the problems in obtaining healing fracture tissue (callus) from human patients and distinguishing bonemarrow-derived ECs from native ECs, this may be difficult to determine. Studies with lac Z (endothelium specific receptor for angioprotein 1) tie-2 and gene positive allogenic bone-marrow transplantation are necessary to confirm that bone-marrow derived EPCs do indeed participate in neovascularisation. Also, in acknowledging experimental evidence of a vasculogenic response to muscle and vascular injury, it is difficult to differentiate injury to bone or to soft tissue as the primary stimulus. We can therefore only conclude that there is a response to musculoskeletal trauma.

We have explored in isolation the neovascularisation component of bone healing. Bone-marrow progenitor cell responses to musculoskeletal injury would not, however, be expected to be confined to the vascular component of bone healing. Shirley et $\mathrm{al}^{37}$ have used a rabbit ulnar osteotomy model to trace the movement of fluorescently-labelled osteogenic cells from tibial bone marrow. The data suggest that some osteoblasts involved in fracture healing were systemically mobilised and recruited to the fracture from remote sites of bone marrow. ${ }^{37}$ While the molecular mechanisms responsible for osteoprogenitor mobilisation have not been explored, a role for VEGF has been determined in both endochondral and intramembranous ossification at various stages of fracture healing. ${ }^{5}$

We have demonstrated that bone marrow EPCs $\left({ }^{\text {sca- } 1+, \mathrm{c}-\mathrm{kit}+}\right)$ with the potential to differentiate into functional endothelium are mobilised after acute musculoskeletal trauma. While recent studies have demonstrated a therapeutic role for angiogenic cytokines in promoting classical angiogenesis, in the absence of a competent responsive population of ECs the effect of administering these cytokines will be limited.

By the manipulation of EPC kinetics, the systemic vasculogenic response demonstrated in our study may offer an alternate therapeutic pathway in the management of aberrant wound and fracture healing.

No benefits in any form have been received or will be received from a commercial party related directly or indirectly to the subject of this article.

\section{References}

1. Folkman J. Tumor angiogenesis. Adv Cancer Res 1974;19:331-58.

2. Folkman J. Tumor angiogenesis. Adv Cancer Res 1985;43:175-203.

3. Eckardt H, Ding $\mathbf{M}$, Lind $\mathbf{M}$, et al. Recombinant human vascular endothelial growth factor enhances bone healing in an experimental nonunion model. J Bone Joint Surg [Br] 2005;87-B:1434-8.

4. Geiger F, Bertram H, Berger I, et al. Vascular endothelial growth factor gene-activated matrix (VEGF(165)-GAM) enhances osteogenesis and angiogenesis in large segmental bone defects. J Bone Miner Res 2005;20:2028-35.

5. Street J, Bao M, deGuzman L, et al. Vascular endothelial growth factor stimulated bone repair by promoting angiogenesis and bone turnover. Proc Natl Acad Sci USA 2002:99:9656-61.

6. Tarkka T, Sipola A, Jamsa T, et al. Adenoviral VEGF-A gene transfer induces angiogenesis and promotes bone formation in healing osseous tissues. J Gene Med 2003:5:560-6.

7. Beam HA, Parsons JR, Lin SS. The effects of blood glucose control upon fracture healing in the BB Wistar rat with diabetes mellitus. J Orthop Res 2002;20:1210-16.

8. Lorenzi M, Nordberg JA, Toledo S. High glucose prolongs cell-cycle traversal of cultured human endothelial cells. Diabetes 1987;36:1261-7.

9. Macey LR, Kana SM, Jingushi S, et al. Defects of early fracture-healing in experimental diabetes. J Bone Joint Surg [Am] 1989;71-A:722-33.

10. Salameh A, Zim M, Dhein S. High D-glucose induces alterations of endothelial cell structure in a cell-culture model. J Cardiovasc Pharmacol 1997;30:182-90.

11. Tirziu D, Moodie KL, Zhuang ZW, et al. Delayed ateriogenesis in hypercholsterolemic mice. Circulation 2005;112:2501-9.

12. Chen F, Osterman AL, Mahony K. Smoking and bony union after ulna-shortening osteotomy. Am J Orthop 2001;30:486-9.

13. Daftari TK, Whitesides TE Jr, Heller JG, et al. Nicotine on the revascularization of bone graft: an experimental study in rabbits. Spine 1994;19:904-11.

14. Lu C, Miclau T, Hu D, et al. Cellular basis for age-related changes in fracture repair. J Orthop Res 2005;23:1300-7.

15. Sadoun E, Reed MJ. Impaired angiogenesis in aging is associated with alterations in vessel density, matrix composition, inflammatory response, and growth factor expression. J Histochem Cytochem 2003:51:1119-30.

16. Asahara T, Murohara T, Sullivan A, et al. Isolation of putative progenitor endothelial cells for angiogenesis. Science 1997;275:964-7. 
17. Asahara T, Takahashi $\mathbf{T}$, Masuda $\mathbf{H}$, et al. VEGF contributes to postnatal neovascularization by mobilizing bone marrow-derived endothelial progenitor cells. EMBO 1999;18:3964-72.

18. Asahara T, Masuda H, Takahashi T, et al. Bone marrow origin of endothelial progenitor cells responsible for post natal vasculogenesis in physiological and patholog ical neovascularization. Circ Res 1999;85:221-8

19. Bailey AS, Jiang S, Afentoulis M, et al. Transplanted adult hematopietic stems cells differentiate into functional endothelial cells. Blood 2004;103:13-19.

20. Boissan M, Feger F, Guillosson JJ, Arock M. c-Kit and c-kit mutations in mastocytosis and other hematological diseases. J Leukoc Biol 2000;67:135-48.

21. Condon ET, Wang JH, Redmond HP. Surgical injury induces the mobilization of endothelial progenitor cells. Surgery 2004;135:657-61.

22. Jackson KA, Majka SM, Wang $\mathbf{H}$, et al. Regeneration of ischemic cardiac muscle and vascular endothelium by adult stem cells. J Clin Invest 2001;107:1395-402

23. Hiltunen A, Vuorio E, Aro HT. A standardized experimental fracture in the mouse tibia. J Orthop Res 1993;11:305-12.

24. Horejsi V, Drbal K, Cebecauer M, et al. GPI microdomains: a role in signalling via immunoreceptors. Immunol Today 1999;20:356-61.

25. Simons K, Toomre D. Lipid rafts and signal transduction. Nat Rev Mol Cell Biol 2000;1:31-9.

26. Yutoku M, Grossberg AL, Pressman D. A cell surface antigenic determinant present on mouse plasmacytes and only half of mouse thymocytes. J Immuno $1974 ; 112: 1774-81$
27. Broudy VC. Stem cell factor and hematopoiesis. Blood 1997;90:1345-64.

28. Heissig B, Werb Z, Rafii S, Hattori K. Role of c-kit-Kit ligand signaling in regulating vasculogenesis. Thromb Haemost 2003;90:570-6.

29. Lin Y, Weisdorf DJ, Solovey A, Hebbel RP. Origins of circulating endothelial cells and endothelial outgrowth from blood. J Clin Invest 2000;105:71-7.

30. Gehling UM, Ergun S, Schumacher U, et al. In vitro differentiation of endothelial cells from AC133-positive progenitor cells. Blood 2000;95:3106-311.

31. Murayama T, Tepper OM, Silver M, et al. Determination of bone marrow-derived endothelial progenitor cell significance in angiogenic growth factor-induced neovascularization in vivo. Exp Hematol 2002:30:967-72.

32. Ferrara $\mathbf{N}$, Carver-Moore $\mathbf{K}$, Chen $\mathbf{H}$, et al. Heterozygous embryonic lethality induced by targeted inactivation of the VEGF gene. Nature 1996;380:439-42.

33. Iwaguro H, Yamaguchi J, Kalka C, et al. Endothelial progenitor cell vascular endothelial growth factor gene transfer for vascular regeneration. Circulation 2002;105:732-8.

34. Shalaby F, Rossant J, Yamaguchi T, et al. Failure of blood-island formation and vasculogenesis in Flk-1-deficient mice. Nature 1995;376:62-6.

35. Takahashi T, Kalka C, Matsuda H, et al. Ischemia- and cytokine-induced mobilization of bone marrow-derived endothelial progenitor cells for neovascularization. Nat Med 1999;5:434-8.

36. Laing AJ, Dillon JP, Street JT, et al. Mobilisation of endothelial precursor cells: a systemic vascular response to musculoskeletal trauma. J Orthop Res 2006;in press.

37. Shirley D, Marsh D, Jordan G, McQuaid S, Li G. Systemic recruitment of osteoblastic cells in fracture healing. J Orthop Res 2005;23:1013-21. 